\title{
3 The human factor - garbage producers
}

This chapter concentrates on the residents of Beijing who produce garbage every day. On the basis of interviews and field data gathered in spring 2017, I focus on the following questions. Where do Beijingers stand when it comes to dealing with the waste they produce? Are they aware that their increased consumption exacerbates the problems related to its disposal? Are they inclined to embrace the circular economy and start to reduce, reuse, and recycle? What do they think about garbage retrieval services like the new $\mathrm{O}_{2} \mathrm{O}$-companies introduced in the previous chapter?

\section{Residential communities}

At the risk of oversimplifying, Chinese urbanites tend to reside in xiao $q u$ ('residential communities') of approximately 2000 households each. A number of these residential communities are overseen by residents' committees, which in turn are grouped together into shequ ("neighbourhood communities'). These fall under the jurisdiction of street affairs offices, which fall under one of the sixteen urban or suburban $q u$ (district governments) (Ngeow, 2012; Teets, 2013: 8; Hu, Tu, and Wu, 2018). Large parts of the housing stock that presently make up the residences of a residential community were originally distributed and managed by the danwei ('work unit') (Gu, 2001: 95). During the Maoist era, these work units together served as a 'mini-welfare state' (Gu, 2001: 91) for urban workers, as they were responsible for 'providing employment; collecting taxes; allocating welfare resources; monitoring and controlling the movement of employees; certifying births, deaths, and marriages; and implementing government policies' (Ngeow, 2012: 77). The danwei system made urban workers highly dependent on their units and, by extension, the state (Dutton, 1998: 42-61; Gu, 2001: 92). By the 1990s, financial constraints had forced the work units to relinquish most of their welfare functions, including housing, medical care, education, childcare, etc. The housing stock that had been at the disposal of the work units was sold off, often for a discount, to the people inhabiting it (Davis, 2005; Yang and Shen, 2008; $\mathrm{Hu}, \mathrm{Tu}$, and $\mathrm{Wu}, 2018$ ).

Even after urban construction took off in Beijing in the 1980s, the former work units continued to dominate the housing market. They negotiated preferential prices for their employees when new housing projects were constructed for sale. Many inhabitants of residential communities feel a 
sense of pride and belonging, based on the fact that they were among the original occupiers of an apartment owned or sold by their work unit. In the eyes of many, attachment to a state-owned enterprise, however virtual this link may seem now, elevates one's position and raises one's social capital. Over the intervening years, many of the original inhabitants of the residential communities have moved on to larger apartments or to other cities and have sold or sub-let their original place of living ( $\mathrm{Hu}, \mathrm{Tu}$, and $\mathrm{Wu}, 2018)$. This has led to a situation where the original inhabitants who continue to live in the community see themselves as having a higher quality, or suzhi, than the newcomers. The importance of this concept of 'quality' is discussed in more detail in Chapter 5 . The 'new' residents have no shared history or experiences with the first generation of inhabitants and have no ties to the original community, as they moved in comparatively recently.

Housing has become a marker of consumerism and thus of status. The neighbourhood and location of one's dwelling confers status. Most commonly encountered are: commercial housing communities, gentrified and often gated, that have higher status; and old or after-sale public housing communities, i.e., housing that has been sold off by state-owned enterprises to former employees. There are also hybrid forms (Hu, Tu, and $\mathrm{Wu}, 2018)$. Even more important, although less visible, than the location of the apartment is the way in which it is furnished (Fraser, 2000; Davis, 2005). As the government's attention shifted away from almost exclusive concern for ideological conformity to economic development under the Reform policies of the 1980 s, the act of consuming came to be inscribed with political meaning. Buying things supported the development of the economy; buying more not only served to demonstrate support for the new policies, but also signified a kind of distinction, replacing other erstwhile ideological and political markers such as class background (Li, 2010: 153).

\section{Municipal classification and separation pilots}

Since 2000, the Beijing municipal government has tried to get its citizens to classify and separate their garbage. Many other urban centres in China (Shanghai, Hangzhou, Suzhou, and Shenyang, to name just a few) have also attempted the same, using a variety of approaches. The Beijing government has resorted to using a number of methods, many introduced on a trial basis in designated residential communities. It has installed separate garbage bins for different categories of garbage for household use; it has made colour-coded garbage bags available to make sorting easier; it has 
Illustration 3.1 Communal garbage bins on the grounds of a residential community. The sign indicates which garbage needs to go into which bin

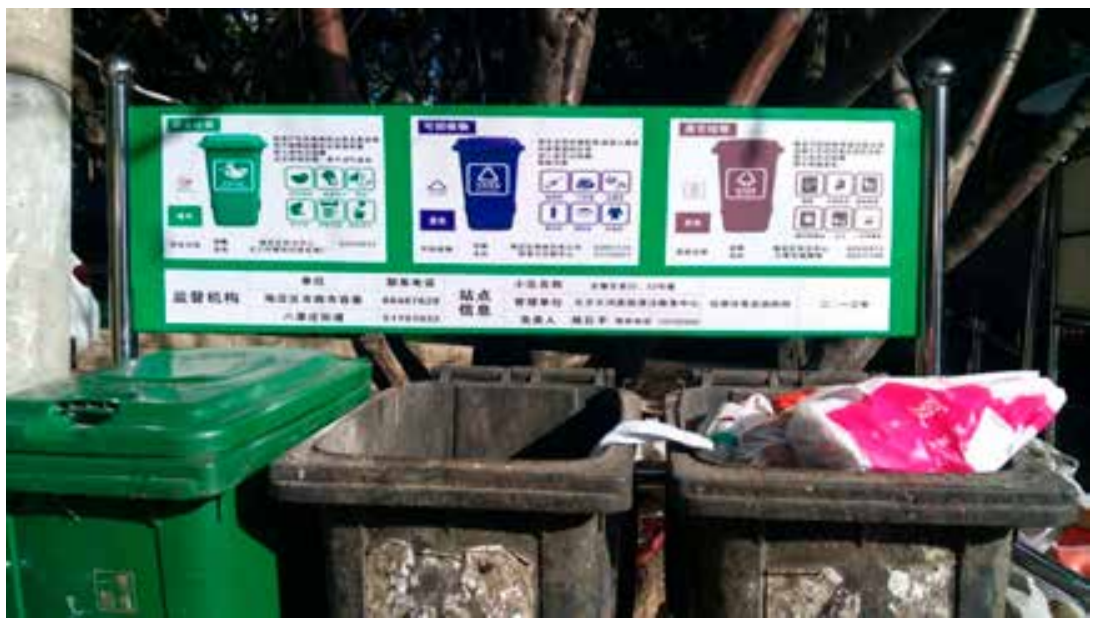

Author's photograph, May 2017

experimented with user fees on the basis of the principle that the polluter pays; and so on (Yuan et al., 2016) (Illustration 3.1). Each of these methods has had some successes as well as failures, and none has made it beyond the pilot stage. The number of residential communities where garbage classification regimes were practiced increased from 600 in 2010 to more than 2400 in 2012 (Friends of Nature, 2013; Yang, 2013; Yuan and Yabe, 2014). I was surprised to find that many residents of such pilot communities had not been informed of the fact that they were taking part in an experiment. They had no idea that their behaviour was part of higher government plans and as a result were not familiar with the aims and targets of the movement. This had a negative effect on their motivation to seriously participate.

In all of these experimental cases, the municipal administration shifted the burden of the implementation to the street affairs offices' levels, who have shifted it to community levels, who have shifted it to, finally, the community management offices that are responsible for the actual community. No matter which method has been attempted in whichever urban centre or district, the citizens have not made any commitment to embrace any of the schemes, citing various reasons why they still do not classify and recycle their waste. These range from lacking space in their apartments to the fact that recycling activities were too cumbersome or confusing. When trying to determine the reasons for this tendency to not participate fully, 
Illustration 3.2 A signboard put up in a residential community providing information on garbage classification and separation. The message stuck on the board urges people to dispose of their garbage in the bins, in order to promote civilization and health

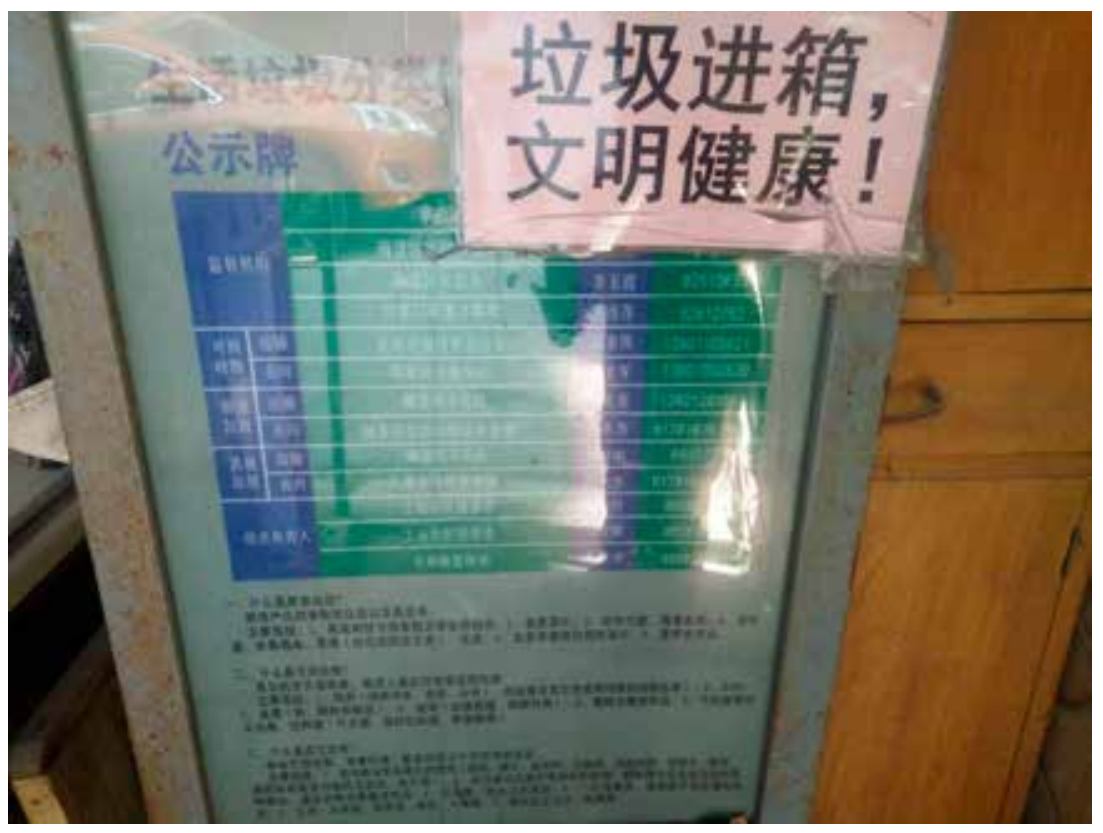

Author's photograph, May 2017

Yuan et al. (2016) have concluded that active citizens' resistance, political complexities, and cultural origins are behind the lack of success when it comes to fostering structural, long-lasting recycling behaviour. As Simões has argued, 'citizens are not necessarily willing to be informed and - more importantly - to act properly upon that information. Individuals are free to refuse such information, to ignore it, or not to change their behaviour' (2016, no page). According to some of my sources who have been keeping track of the various (municipal) campaigns to make garbage separation an inalienable part of daily life, local governments have not performed well in the disposal of garbage in general. After all, it does not make any sense to separate one's garbage when the sanitation department is not equipped to dispose of the garbage adequately or when separated waste treatment is not in place in general (Martens, 2006). Some of the trial projects ended up as merely face-saving efforts, with the responsible departments only going through the motions of taking action. In the case of Beijing, for 
example, some districts enlarged the garbage bins in their areas or provided garbage bins with openings for separate types of waste, but with only a single receptacle under the lid, turning the separation activity into a farce; or they installed an embryonic information collecting system that quickly sputtered out; none of these measures actually succeeded in changing the habits or behaviour of the residents (PKU MBA Deep Dive, 2015; Interview with Hong Chao, 2017) (Illustration 3.2).

\section{Gender and garbage}

At this point, it is relevant to point out that the practices involved in garbage disposal, classification, and/or separation in the urban configurations I studied in Beijing are gendered activities. It is usually the women in the household who are responsible for the garbage and this situation certainly is not unique for Beijing (Li S., 2002: 794-796). In the interviews and informal talks I held with community residents, the female respondents often indicated that they were the ones who actually dirtied their hands doing the garbage. Based on the manner in which they talked about these topics, it was clear that this was completely natural in their opinion, as it was part of how they visualized their housekeeping work. Many of the housewives expressed a desire to take a more active part in waste reduction and/or garbage classification and separation, thus offering more of a personal contribution to improving the environment for the next generation. But they also let it be known that they simply did not know how, were not told what to do beyond what they already knew about, i.e., selling the most valuable recyclables (Zhang and Wen, 2014; Interviews, 2017).

Their spouses or the other male residents present were quick to explain that they were just as involved in keeping the house clean of garbage as their wives were. They insisted quite vocally that taking care of the garbage was a man's job, and therefore they saw it as their responsibility. The wives often furtively made clear that this was just empty talk. Some male residents specifically mentioned the fact that garbage disposal (but not separation) was something that all household members, including the children, participated in. These fathers suggested that the matter of garbage was a subject they discussed often in the household. It offered them ample opportunities to teach the younger members of the family about values and social responsibilities. Indeed, the male members of the household tended to be quite familiar with and supportive of the current phrases, slogans, and concepts that were used by the government or community 
management offices when I talked with them; they quoted them often and literally (Interviews, 2017).

Some of the children who were around during the interviews with their parents did not take part in classifying or recycling at all. As members of the One Child and post-1980s or -199os generation, they usually were not asked to do anything in the household but were instead told to concentrate on their studies; the future welfare, wellbeing, and status of the family depended on them alone (Fong, 2004). The small number of kids who occasionally were ordered to dispose of the garbage made no secret of the fact that they loathed it; most said that this was something Mom usually did, or should be doing, not their job. Similarly, they had no clear ideas about the details of garbage disposal or how to classify and separate waste; these activities were simply not within their sphere of interest and they could not be bothered about them, simply dumping their waste wherever was convenient (Interviews, 2017).

\section{Age and garbage}

In talks, interviews, and discussions, elderly citizens tended to complain about the fact that the younger generation did not care a bit about recycling. The older people were quick to characterize children as a throw-away generation, disposing of the waste they generated without a second thought. Their own traditional values of communist austerity where it concerns the use of things were overturned by the values of consumerist hedonism embraced by the generations that were born after the 1970s (Wang, 2002; Li S., 2002; Simões, 2016). As these older generations fade away, their recycling values and knowledge rooted in practical economic and environmental awareness are also disappearing (Williams, 2014: 296). The idea that the elderly are more conscious of separating and recycling also was reflected in the educational materials produced by the Solid Waste Management Office of the Beijing Municipal Appearance Management Committee, which are analysed and discussed in more detail in Chapter 5 . These publications present the grandmothers - and only occasionally grandfathers - as the ones who are fully aware of what to do with the garbage and how to sort and separate it, as opposed to the other members of the family. In popular perception, the elderly do not need to be told or educated.

Retirement starts early in China, although steps are underway to raise retirement age. Urban women working for a state enterprise or private company can retire when they are 50 years old, while men usually work until 
they are 6o; civil servants generally work five years longer than enterprise employees. For urban workers, 54 years is the average age of retirement. Upon retiring, urban workers can expect to receive about 2000 yuan per month. This is in stark contrast with farmers, who receive only 70 yuan per month once they have passed their 6oth birthday, if they are lucky (Shi et al., 2015). Pensions are just another part of the basic provisions that are bound up with the hukou ('Household Registration System'), which favours urbanites over the rest of the population (discussed in more detail in Chapter 4). Migrant workers in urban areas can claim a pension, but only in the place they have been registered.

Many of the elderly people one encounters in town often give an impression of having a carefree existence; still, they make a point of collecting recyclables wherever and whenever they can. One rarely spots an old person without a shopping net or shopping cart, often filled with empty plastic bottles. Well-dressed pensioners, usually women, sorting through trash cans is a sight frequently seen. Many insist that this sort of activity keeps them spry and energetic, as if recycling is part of some self-designed fitness programme. They also make clear that they see their hunt for recyclables as a civic duty, and as part of their suzhi ('quality'). Many talk with disdain about young people in general, and express their disgust with the ease with which the latter consume and simply throw stuff away, preferably making an effort not to put their trash into the waste bins. The fact that the elderly show a higher awareness of wastefulness and recycling should not come as a surprise. Many of them have lived through times of hardship and want; many have witnessed periods of famine and destitution (Evans, 2014; Wang et al., 2016); many were thoroughly socialized in the 1950s and later to collect junk for the state, with the result that they see recycling as an essential activity (Li S., 2002).

Most of my elderly conversation partners scoffed at my suggestion that their pensions were inadequate and that they needed the extra income they could earn by selling used bottles or other valuable junk. They very carefully explained that they were well taken care of by the government. Rather, they said, collecting recyclables is like finding free money on the street that can be spent on the grandchildren or to do something special for themselves (Li S., 2002; Goh, 2009; Griffiths, 2014; McKinsey \& Company and Ocean Conservancy, 2015; Interviews, 2017). In opposition to these apparently carefree retirees, there are large numbers of elderly people, both male and female, who do not create the impression that they dig through trashcans for fun. This is not limited to specific parts of the city, but they are generally more active in the poorer sections and neighbourhoods. It is often hard to 
distinguish whether these individuals are part of the growing numbers of the urban underclass, made up of former state-owned enterprise workers who have been made redundant, or elderly migrant workers (Zhang, 2002; Solinger, 2004; Liu and Wu, 2006; Saunders and Sun, 2006; Gao and Zhai, 2017). Many depend on recycling PET bottles and other items of recyclable garbage simply to survive; with no or inadequate pensions to fall back on, their income derives from whatever they can earn from sorting, collecting, and selling waste (Solinger, 2006; Taylor, 2008; Griffiths, 2014; McKinsey \& Company and Ocean Conservancy, 2015; Gao and Zhai, 2017; Fieldnotes, 2015, 2017; Interviews, 2017).

\section{One false move}

Recycling initiatives tend to fail when the residents are insufficiently convinced of the effectiveness of their separating behaviour, whether this is newly acquired or deeply ingrained. One experience that I heard recounted often, told by people living in different communities as well as environmental NGO representatives, is how garbage that the residents had carefully classified and separated ended up in one single individual all-purpose garbage truck and got mixed with the other unsorted garbage (Friends of Nature, 2013; Interviews, 2017). Talk about such incidents, even if they occur only one time, tends to continue forever. People return to the topic over and over again. And it makes those willing to classify and separate start to wonder why they should bother at all, when in the end it all ends up in the same truck, the same landfill, or the same incinerator anyway (Martens, 2006). Research has shown that in many communities, no information was provided, for example on notice boards, about where the carefully classified and separated garbage would end up. This had a negative effect on the possibility of motivating the residents (Friends of Nature, 2013)

Despite this, further research has shown that 59 percent of Beijing's residents said that they were aware of the seriousness of the city's garbage problem. The ENGO Friends of Nature discovered in 2012 that 71 percent of the residents reported that they classified and separated garbage at home, while only 63 percent did so in 2010. All the same, many admitted that they had never heard of garbage classification and separation, and multiple reasons stopped people from doing so. Some said that they lacked awareness and could not adopt the habit; some thought it should be the responsibility of the real estate company or the community management committee, as they had already paid them fees. Some said they could not be bothered, especially after 
a heavy day's work. Some found it unnecessary; others felt less motivated when fellow residents did not do the same (Friends of Nature, 2013).

This corresponds well with the results of my own interviews. Many people insisted that they duly classified and separated their garbage into recyclables, non-recyclables, and plastics. As Tang, Chen, and Luo have established, however, 'self-reported recycling behaviour and recycling behaviour itself are not tantamount' (2011: 860). Other interviewees, often those who lived in communities that had been designated as experimental bases for waste separation by the municipal government, indicated that they even went beyond what was required and had started to separate their kitchen waste as well. In some communities, green kitchen waste containers had been introduced and installed with clear usage instructions (Friends of Nature, 2013; Yuan et al., 2016). Practically all of the interviewees had heard or read stories, online or in newspapers, or had seen TV programmes that reported on the more advanced and sophisticated waste separation practices in Japan, Taiwan, and elsewhere (Ding, 2016; Huishouge, 2017a). Although they admired these examples and considered them interesting and potentially relevant, the Beijingers still saw them as 'foreign' - and this was usually the most explicit reason given for not following them. Aside from offering arguments that such practices were not Chinese, residents in general said the lack of space in their apartments was one of the main reasons they did not classify their garbage into more narrowly defined categories. This did not stop them, however, from using hallways and other shared spaces to store goods they did not (seem to) use any longer (Fieldnotes, 2015, 2017; Interviews, 2017). The knowledge needed for garbage separation into the detailed categories that are in use in Japan and Taiwan is completely non-existent among Beijing community residents, particularly when set against their general lack of understanding about the need and urgency to start doing so. They attributed their lack of awareness to the fact there are no structured or continuous propaganda or educational programmes or information drives about these topics. While Minter (2013a, 2013b, 2015) and others (Li S., 2002: 788-794; Interviews, 2017) convincingly argue that Chinese are very knowledgeable about the potential sales value of their waste, other sources stressed that Chinese consumers have no clue that their waste is worth something - that, for example, white plastic recyclables sell for a different price than black or coloured plastics, or that transparent glass is re-used differently than coloured glass. The sources who stressed the need to make residents aware of the value of recyclables were convinced that once they became aware of the opportunity to earn money, more residents would be willing to start recycling (Interview with Hong Chao, 2016). 
Illustration 3.3 Coloured communal garbage bins on the grounds of a Haidian District residential community

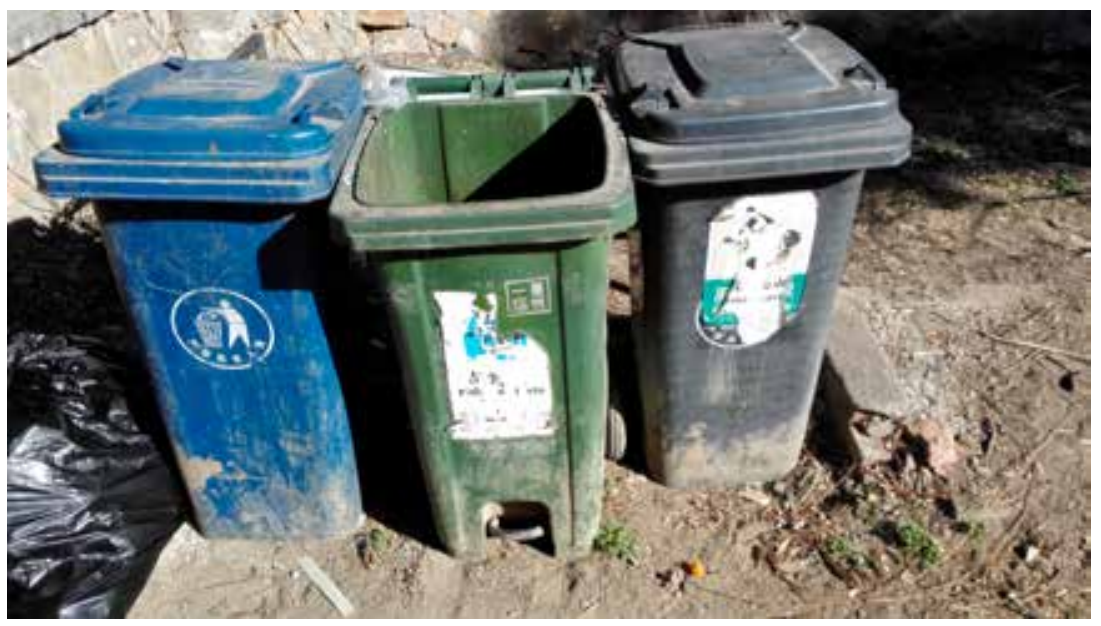

Author's photograph, April 2017

Most residents live in communities that have three communal garbage containers (one for recyclables, one for non-recyclables, and one for plastics) in the yard, or combinations of this configuration (Illustration 3.3). They consider it less cumbersome to hop down the elevators several times a day to deposit their waste in the container they think is designated for their specific type of waste than to keep the garbage indoors in some special receptacle for future disposal. Those who had not taken part in any of the experiments related to kitchen waste were convinced that having to store food waste indoors would surely be a nuisance, particularly in summer when it quickly developed noxious smells and attracted all sorts of unwanted vermin. They were not sure whether they would ever start separating their kitchen waste for this reason (Interviews, 2017).

Many of the middle-class residents confessed that although they had classified and separated their garbage before, they had stopped doing so for various reasons. This change in behaviour most certainly was not the result of a sudden decrease of 'quality' that they might have suffered. On the contrary, almost all of them prided themselves on their high levels of environmental awareness, and many mentioned that they had taken an active part in projects that had been organized in their communities and/or by ENGOs. They were generally outspoken about the need to classify and recycle and expressed their desire to help make the world a 
better place to live, both for themselves and for their children. But still they had given up separating their garbage, often after a rather short period of time. Since they did not feel good about their actions, they said that others were responsible for making them stop, or at least for not supporting their classification and separation efforts. Those 'others' had persuaded them that it all cost too much energy and involved too much trouble. This happened in particular in communities where there was a 'guy downstairs' who collected, separated, and sold the community's garbage for a living. Why then should they bother to spend energy on these activities (Interviews, 2017)?

\section{The 'guy downstairs'}

This introduces the phenomenon and importance of the 'guy downstairs' into the discussion. The 'guy downstairs' is a fixture in the chain of urban recycling that has evolved in Beijing and other urban centres. These 'guys downstairs' are more often than not actually husband-and-wife teams, members of the army of migrant labourers from the countryside. They may have started out as waste pickers roaming the streets, scouring waste bins, and hunting for recyclables. In one way or another, they have had the opportunity to formalize these activities by offering their services to a residential community while still maintaining their independence and remaining part of the informal sector of waste collectors. They often have been invited by the community management office or real estate agency to take care of the solid recyclable waste without being offered formal employment. Others have 'bought' the right to collect the recyclables of 'their' specific residential community (Ensmenger, Goldstein, and Mack, 2005; China Youth News, 2016; Interviews, 2017). Over time, some have become such fixtures in the communities where they ply their trade that they consider them to be their actual posts. In many communities, these waste collectors actually occupy a portacabin-like cubicle from which they operate and where they store recyclables awaiting transportation upstream (Beijing Municipal Urban Management Committee and Beijing Municipal Urban Management Committee Information Center, 2017: 2). Their scrupulous sorting of garbage complements the hauling work done by the city garbage collectors who come and empty the bins in the yard. The 'guys downstairs' have a negotiated yet informal base of operations and generally are responsible for maintaining the yard; in short, their job is to keep the community in tiptop shape. Their income is based on whatever 
price they are able to negotiate for the recyclables they have collected (Interviews, 2017).

In terms of work conditions, having a semi-permanent, semi-formal job within a community is seen by many migrant workers as a step up, as a symbolic improvement of their lives, almost like having steady work while still remaining employed informally, with all the connotations of being an independent operator (Ezeah, Fazakerley, and Roberts, 2013). Given its semi-formal characteristics, this type of employment does not qualify the 'guy downstairs' to apply for an urban registration. As informal garbage workers, they are considered inferior; without an urban registration, they can be nothing but sojourners, of the place, but not from the place. This stands in stark contrast with the attitudes that reportedly prevailed in Beijing during the Republican era (Goldstein, 2006). Given the possibilities of rich yields of recyclables, these in-yard posts are much sought after. They could serve as the starting point to develop more structural sustainable community activities, depending on whether a migrant worker or potential 'guy downstairs', is willing and able to take initiatives (Tong and Tao, 2016).

Not many respondents had personal contacts with 'guys downstairs', nor were they particularly cordial or close. Their interactions were fleeting, not going beyond an occasional greeting every once in a while, or a casual 'here you are' remark when handing over a piece of recyclable garbage. Many residents did mention that they put their recyclables not inside the garbage bins but on top of or next to them, making it easier for the 'guy downstairs' to separate and collect. These 'guys downstairs' simply were there, human beings that community members did not need to acknowledge. In many cases, the residents did not register their presence at all, or suggested that they had already left the community to go to work by the time the 'guys downstairs' entered. In a few instances, respondents actually said that these people were too uncultured (in the sense of lacking 'quality'), too dirty, too malodorous to communicate with; others hinted that they could not be trusted, that they had criminal leanings (Mobrand, 2006; Tse, 2016; Interviews, 2017). In short, the people working in the yards collecting garbage were tolerated. Many suggested that elderly residents might have closer relations with these 'guys downstairs' or strike up friendships with them, often looking out for them and being solicitous about their wellbeing. But this was attributed to the fact that the elderly were always looking for some company, somebody to talk to in order to while away the time. And the people working in the yards were also ideal sources of gossip, as they observed the daily comings and goings of the residents. 


\section{Case study of Red Nest Community Resource Centres}

The phenomenon of the 'guy downstairs' has gone through an $\mathrm{O}_{2} \mathrm{O}$ metamorphosis under the Internet Plus Recycle plan, similar to the transformation of the door-to-door recyclable collection process. In cooperation with the Synergy and New Ecology Design Centre of Tsinghua University and the Urban Development and Environment Research Centre under the Chinese Academy of Social Sciences, the Hong Chao (Red Nest) Enviro-Tech Company has developed an approach that modernizes the collection activities undertaken by persons in the yard. The aim of this solution, which combines $\mathrm{O}_{2} \mathrm{O}$ and $\mathrm{M}_{2} \mathrm{M}$ (machine-to-machine) technology, is to extract big data from collection activities; to streamline the collection, disposal, and recycling of waste materials; and to provide continuous educational moments and awareness-raising opportunities among the community residents. This approach has been chosen on the basis of extensive research in communities in Hebei Province and Beijing proper that was undertaken by the three units involved. One of the outcomes of the preliminary research was that the majority of respondents were highly motivated to engage in garbage separation and recycling, but unable to do so for several reasons: first, they lacked knowledge and understanding of the process; second, the governments at various levels had failed to make clear why such behavioural change was necessary; and third, the respondents felt that the existing garbage disposal system was unsatisfactory and lead to undesired secondary pollution. This secondary pollution was partly the result of the too-infrequent visits of garbage trucks coming to empty the communal bins, partly of waste pickers' continuous rummaging through the often-overflowing bins. In Spring 2017, the Hong Chao company had been running a number of pilot sites in selected residential communities for some 15 months. Some of these pilot sites were designated after prolonged negotiations with local governments; some joined the scheme voluntarily. The Hong Chao company entertains the idea that in the future, after a prolonged period of testing and community presence, it will be able to play a role in providing the government with the data needed to formulate policies that aim to make the user pay for the garbage s/he disposes of (Interview with Hong Chao, 2017).

The forms and functions of these Red Nests, termed 'Community Resource Centres', are not altogether new. In various residential communities, the waste collectors downstairs already operate from a small cubicle of varying quality and comfort (Tong and Tao, 2016; Fieldnotes, 2015, 2017; Beijing Municipal Urban Management Committee and Beijing Municipal Urban Management Committee Information Center, 2017: 2). Red Nests 
Illustration 3.4 Front view of a Red Nest in a Shunyi District residential community, designed and operated by the Hong Chao (Red Nest) Enviro-Tech Company. Note the RFID tag dispenser

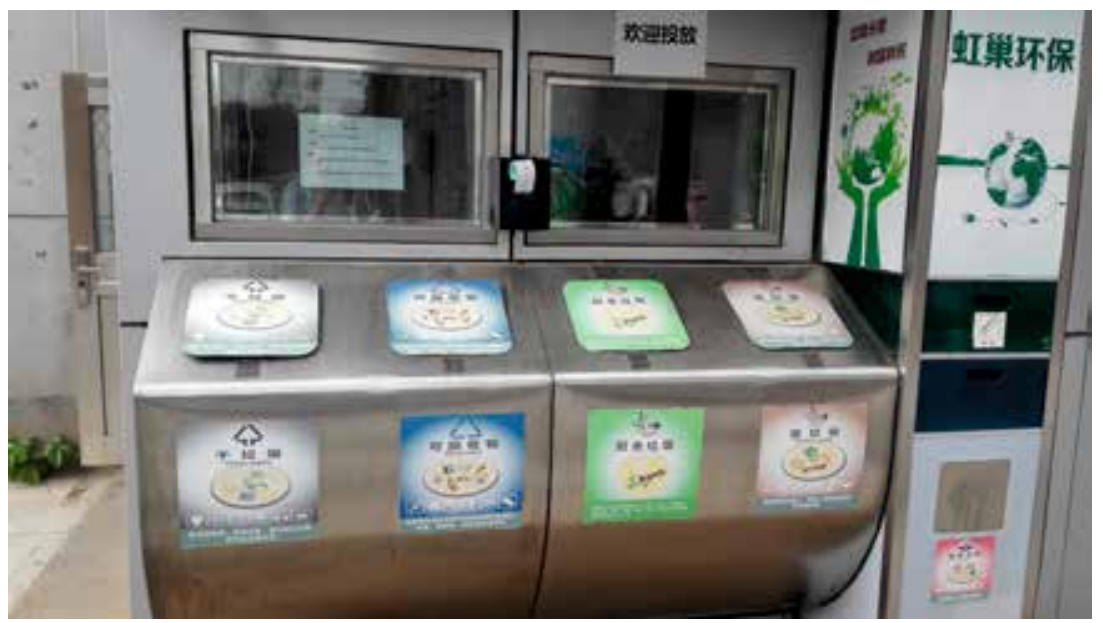

Author's photograph, 4 May 2017

essentially have the same characteristics as the portable buildings, or portacabins, which are already in use in many communities. This makes them ideally suited for introduction to pre-existing built environments and communities where no such services had been offered before: they may be new, but in essence they are not. Despite the pre-fabricated and familiar appearance, it is obvious that a serious amount of design has been involved in the way the Red Nest structure looks and the many functions it has. The Nests are in fact small collection stations. The facade of the Nest is fronted by two sliding windows with four hoppers underneath, each clearly identified as receptacles for valuable, dry, wet, and poisonous waste by means of stickers with cartoon symbols. These symbols have been designed in such a way that even illiterate people can understand what type of waste should go where. Waste that is too bulky to fit in the hoppers can be delivered through the windows or the door. Slightly to the right and stretching the full height of the structure is a column for the disposal of batteries and e-waste. To the right, a video screen broadcasts looping messages about separation, recycling, and other related topics. On the roof of the structure a battery of solar energy collectors is mounted, providing the whole setup with the energy required to operate. A ticket dispenser is mounted above the hoppers, which is activated through a proprietary app that community residents download on their smartphones. 
The dispenser produces RFID-tags that need to be stuck to the garbage that is disposed of in the hopper (Hongchao Enviro-Tech, n.d.; Fieldnotes 2017) (Illustration 3.4).

These RFID-tags are essential for the collection of the big data that will drive the Red Nest network once it has grown, for it is within the portable building that the actual second separation takes place. The interior is dominated by a sorting table in the middle, underneath the sliding windows, with an RFID reader hanging over it. An employee empties the hoppers, scans the RFID tag attached to the waste, sorts it, and disposes of it in one of the numerous designated cabinets that are on the side. These cabinets, which can be accessed from both within and outside the structure, have sensors that keep track of volume and/or weight. Once the cabinets are filled, the system sends a notification to the recycling companies that a certain kind of garbage container is full and ready for pick-up. The recycling companies pay the Red Nest company and move the waste up the stream towards recycling or ultimate disposal (Interview with Hong Chao, 2017).

While the Red Nests serve as collection points where people can drop off their waste, this is not their only or even main function. The proprietary app that the company has developed allows community residents to notify the person(s) manning the Nest that there is garbage to be picked up at their doorsteps. In ways that are similar to the $\mathrm{O}_{2} \mathrm{O}$ companies discussed in Chapter 2, the residents who offer waste for pick-up collect credits that they can use to trade for goods. The garbage thus collected is treated in the same way as the waste delivered to the Nest cubicle proper: it is RFID-tagged and sorted for a second time, thus adding to the body of data that Hong Chao wants to amass. Both the persons offering the garbage and those collecting it should feel more assured: the residents are certain that their waste is dealt with correctly and speedily without having to turn to or wait for outsiders, and the waste retrievers can collect waste more efficiently (Interview with Hong Chao, 2017). Moreover, a system like this is transparent and does not leave room for cheating by waste buyers. It scares off the scavengers who roam communities, ripping open plastic garbage bags and spilling their contents. These were complaints that were voiced in other sources as well as by interviewees (Goldstein, 2006; Interviews, 2017) (Illustration 3.5).

Indeed, one of the most striking characteristics of the Red Nest plan is how it integrates waste separation and disposal within the community and makes it completely visible to all concerned. All interactions between residents and waste workers are regulated and take place in public. This 
Illustration 3.5 A residential courtyard in Haidian District, with three communal bins and a collecting bin for textiles

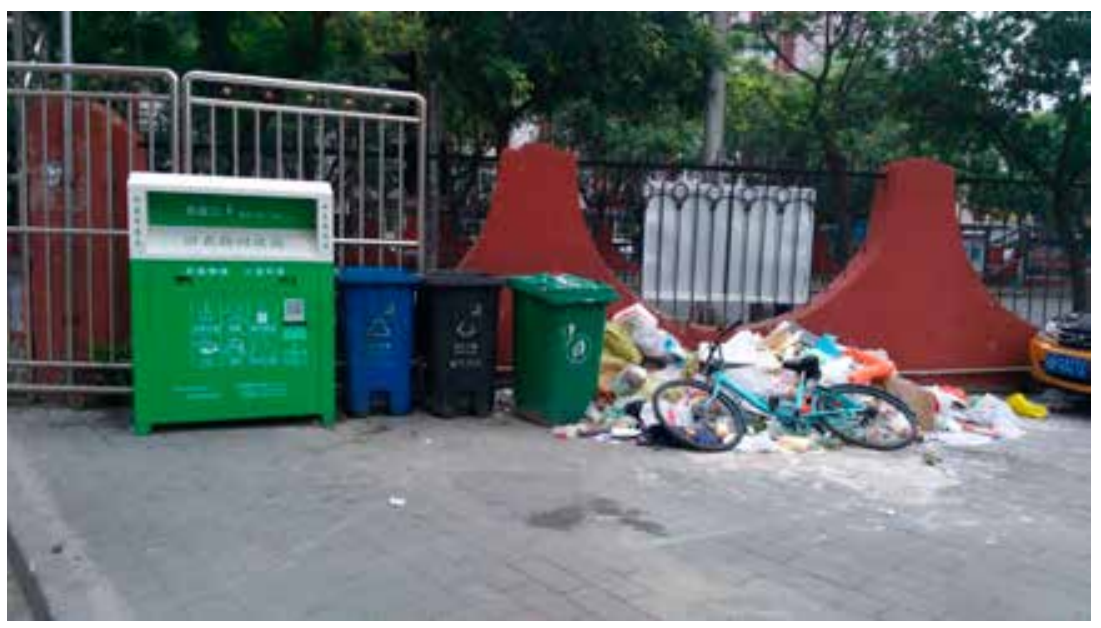

Author's photograph, May 2017

allows for a familiarity to develop between residents and waste workers, which in turn opens up opportunities for continuous education that goes beyond the pasting of slogans or themed posters, or even the materials that are broadcast in endless loops on the video screens of the Red Nests themselves. The regular interactions with the waste worker stationed in the Nest may turn him/her into something of an acquaintance, whose urging to separate and recycle may more easily be taken to heart. Even though they work within a community, the people employed in the Red Nests will never become full members of that community. Having a stationary work spot, however, allows them to work more efficiently, in a better environment, with a fixed income and social benefits (Interview with Hong Chao, 2017).

\section{Using $\mathrm{O}_{2} \mathrm{O}$ apps and services}

The $\mathrm{O}_{2} \mathrm{O}$ companies obviously face stiff competition from initiatives like the Hong Chao solution, because the latter seems much more similar to the existing 'guy downstairs'. Moreover, many of my interviewees indicated that the $\mathrm{O}_{2} \mathrm{O}$ services were completely unknown to them, the potential users. When I explained what the aims of companies like Zaishenghuo, Bangdaojia, and Taoqibao were, how they operated, and how their smartphone apps 
worked, most residents made it clear that they had never heard of these companies or what they offered. They had never seen one of their workers or vans in the streets or in the communities. None of their relatives living nearby or in other parts of the city had mentioned them even once. When asked, some said that they were familiar with the Incom RVMs in the subway stations, maybe had even used them once or twice and found them convenient, but they stated that they would not go out of their way to find one to dispose of a PET bottle. They were not aware that Incom also ran the Bangdaojia service.

My interviewees were not attracted to the potential convenience the apps offered, though they admitted that having service people coming to one's door for small repairs and/or odd jobs did sound very convenient and appealing. According to many respondents, downloading and using an app like this was something that only younger people did, not something for them. This immediately turned the question about whether they would join an $\mathrm{O}_{2} \mathrm{O}$ scheme into a statement that it might attract the younger, higher salaried generations, but it was not something that ordinary people (laobaixing, the 'old one hundred names' is the term my sources would use) would think of doing. They suggested that they considered recycling as something of a daily responsibility that they took care of themselves. They continued to say that the elderly either did not own a smartphone or were not able to operate them. This view was not supported by my own experiences or observations (Fieldnotes, 2015, 2017; Interviews, 2017). Many Chinese media reports show that the elderly are considered to be a particularly promising target group for $\mathrm{O}_{2} \mathrm{O}$ companies (Zheng J., 2017).

Many interviewees contended that they did not need a service in their communities to pick up recyclables on their doorstep, as they already had 'guys downstairs' who took care of the recycling. Moreover, they were convinced that these companies were only interested in specific types of recyclables - valuable ones. They did not perceive any potential of convenience from $\mathrm{O}_{2} \mathrm{O}$ services; instead, they expressed dismay at the idea of having to notify various different companies to help them dispose of their assorted junk. Others were surprised at the various maintenance services offered by the companies. They wondered who would hire such a service: according to them, these things should actually be taken care of by the community management committees, and as residents they had already paid a fee for such work. Why would they pay extra money? Most of my sources also feared that $\mathrm{O}_{2} \mathrm{O}$ services would be picky and difficult to work with, as they were only interested in valuable junk like used smartphones, and not the sort of trash that my interviewees would 
usually have on offer. They seriously wondered why they would ever engage such a service (Interviews, 2017).

Many respondents referred often to worries about what to do with the large numbers of used batteries they ended up with. They were aware of and concerned about the effects on overall pollution that batteries would have, something that must have stuck in their memories after watching television programmes or reading articles in the media. They were generally anxious to dispose of batteries properly, much more than the other waste they generated. This may point to the positive effects that sustained publicity about the negative effects of some goods can have on consumer behaviour. But the anxiety of the respondents made it clear that, while they discussed this problem amongst themselves, no solutions were offered by the management committees or district or city governments to remedy the situation, and no action was undertaken, such as providing special disposal bins for used batteries at strategic spots. When residents suggested solutions to their management committees, they felt that their suggestions were not taken seriously (Interviews, 2017).

\section{Ultra-suzhi}

Some of my scholarly colleagues and friends, though admittedly not a large number, have made a start with their own type of civic action concerning waste disposal. Whenever they see an empty bottle, box, or discarded newspaper lying in the street, they pick it up and dispose of it in the nearest garbage bin. Driven by a sense of propriety, they attempt to educate others by setting an example. In the process, they demonstrate that they have an ultra-high level of suzhi. Many times I have seen astonished and non-comprehending onlookers witness such actions; aside from expressing their surprise, however, they did not seem to be educated or influenced in any way by this exemplary behaviour (Fieldnotes, 2015, 2017).

It is remarkable how this proactive behaviour corresponds with similar phenomena in some Western countries. Well-educated members of the middle classes there have taken to voluntarily cleaning the streets of discarded waste (Dalrymple, 2016). In 2016, a trend of picking up litter while jogging started in Sweden, giving rise to the term 'plogging'. By now, plogging's popularity has reached other countries, where it has, in the eyes of some, become a new fitness craze (Poole, 2018). This practice surely must appeal to a younger generation of health-conscious, exercising Chinese city dwellers, and its effects may be surprisingly positive over the long run. 


\section{Waste and $\mathrm{O}_{2} \mathrm{O}$ services}

Based on the information I collected through interactions with Beijingers, it has become clear that the $\mathrm{O}_{2} \mathrm{O}$ companies have not been successful in their public relations work. None of my sources had ever heard of them, none of them had seen their advertising or seen them in practice. The sole exception were the RVMs operated by Incom, which many had encountered. Some actually used them, sometimes, and in general they liked the idea. Most damaging were the residents' observations that $\mathrm{O}_{2} \mathrm{O}$ services were not needed. They were satisfied with the solutions for the waste disposal problem that already existed and that worked just fine in their opinion. They did want to know more about safe ways to dispose of batteries, and of trustworthy services to help them dispose of used and/or unwanted clothing. A recurrent complaint was that despite their own desire to act and improve the environment, the residents did not know how. In their eyes, the government had failed to tell them what to do and had failed to find a solution for the waste. 
